\section{Impact of dentofacial esthetics in self-esteem. A review of the literature.}

\section{Elizabeth Cofré ${ }^{1} \&$ Katherine Rodríguez ${ }^{1}$}

Abstract: At the national level, it is considered that around half of 12-yearold children have some type of malocclusion. This problem gives rise to negative functional and esthetic consequences that produce a dissatisfaction in the individual, which is related to the severity of the dental irregularities. Even so, there are differences in their recognition and evaluation, given that it is not uncommon to observe some patients with severe malocclusions who are satisfied with their dental esthetics. Physical and facial appearance play a fundamental role in interpersonal communication; therefore, malocclusion can have a negative effect on social relationships, affecting the self-image and self-esteem of individuals. The objective of this article is to describe the results reported in the literature about the impact of dentofacial esthetics on self-esteem. Evidence about the impact of malocclusions and their relationship with general self-esteem and psychosocial disorders of dentofacial esthetics is varied; there is no direct association between these three measurements in all cases. Below, we present some interesting studies and evidence. The studies reveal the association that exists between malocclusion, general self-esteem and psychosocial disorders in relation to dentofacial esthetics. The majority of studies are in adolescent populations at the national and international level. This clearly shows the lack of studies in young or university age populations, which is of interest in dentistry and public health.

Keywords: dentofacial esthetics, self-esteem, self-concept

\section{INTRODUCTION}

Malocclusion is defined as spatial position deviations between teeth, and of these in relation to the jaws. The jaw growth and development of occlusions can be altered by several factors such as genetic factors, growth and development, skeletal factors, muscular factors, dental factors, bad habits, etc., which act to determine the occurrence of a malocclusion (Barrachina, 2000).

Globally, dental malocclusions are the third most prevalent oral health pathology, after tooth decay and periodontal disease. Nationally, in children under 12 years, $47.4 \%$ of the population are considered to be without malocclusion, $15.9 \%$ have a mild abnormality and $36.5 \%$ have a moderate or severe abnormality (Soto et al., 2007).

This problem gives rise to negative functional and esthetic consequences that produce dissatisfaction in the individual, which is related to the severity of dental irregularities. Even so, there are differences in the recognition and evaluation of them, given that it is not uncommon to observe that some patients with severe malocclusions are satisfied with their dental esthetics (de Paula et al., 2009).

Physical and facial appearances play fundamental roles in interpersonal communication; therefore, malocclusion can have a negative effect on social relationships, affecting the self-image and self-esteem of
INT J MED

SURG SCI

Affiliations: ${ }^{1}$ Facultad de Odontología, Universidad Andrés Bello, Concepción, Chile.

Corresponding author: Elizabeth

Cofré. Dirección: Conde de la conquista 198, Hualpén. Phone: +56977551483.

E-mail: e.cofreriquelme@hotmail.com.

Receipt:

04/10/2018

Revised:

04/22/2018

Acceptance:

05/03/2018

Online:

$08 / 30 / 2018$
Conflict of interests: None.

Ethics approval: Not required.

Funding: None.

Authors' contributions: All authors carried out the entire review.

Acknowledgements: None.

doi: $10.32457 / \mathrm{ijmss} .2018 .007$. 
people (Badran, 2010).

The objective of this article is to describe the results reported in the literature about the impact of dentofacial esthetics on self-esteem.

\section{SELF-CONCEPT}

The self-concept is defined as the perceptions that a person has of themselves as an indivisible and global whole; this perception is formulated from their own experiences and influenced by the reinforcements and evaluations of external persons that have a significant role for the individual, in a concept that the individual adopts of himself as a social, physical and spiritual being (Vincent et al., 2015; Pastor et al., 2003; Cazalla \& Molero, 2013).

The importance of self-concept lies in the influence it establishes in the conformation of personality and social competence; it affects how the individual feels, thinks, learns, values himself, and relates to others, and, ultimately it is related to well-being. Many of the current psychological problems such as depression or abuse are related to an altered self-concept (Cazalla \& Molero, 2013).

The general self-concept is determined by the degree of importance given to each of the specific components. For example, if self-described value judgments are satisfactory, a positive general self-concept will be obtained (Cazalla \& Molero, 2013).

The self-concept has a series of characteristics (Vincent et al., 2015; Pastor et al., 2003; Cazalla \& Molero, 2013). It is organized or structured: the experiences of an individual establish the source on which their own perceptions are based. To reduce the complexity of these experiences, the person classifies them into categories which organize their own experiences and give them meaning. It is multidimensional: the different areas reflect the categorization system adopted by an individual or which are established by a group. Perceptions are located at the base of the hierarchy (academic, personal, social and physical). It is stable: however, as one descends in the hierarchy of self-concept, it depends on the situations that occur at a given moment, making it less stable. It is experimental: as age and experience increase, selfconcept becomes increasingly different. It is evaluative: the individual makes a description of himself given a particular situation. Valuations can be made by comparing already established patterns as correct or ideal of society, the environment or itself. It is differential: the self-concept is influenced by specific experiences.

During adolescence, various changes occur, such as the development of cognitive and physical abilities, the appearance of new social and academic roles, which allow a greater level of significance in the selfconcept, the emergence of self-assessment, as well as the predisposition to distort the self-image. In addition, the structuring of the personality takes place through the changes that the individual experiences in corporal and psychological aspects and in their relationships (Vincent et al., 2015; Saliba et al., 2009; Papalia et al., 2009). In this last aspect of relationships, the most influential factor that initially conditions a personal interrelation is physical attractiveness, as well as one's own perception and the assignment of attributes to others (Cazalla \& Molero, 2013).

There are three stages that allow the formation of self-concept (Cazalla \& Molero, 2013). The existential cover or primitive self: from birth to two years, the child develops to be perceived as a reality different from others. The cover of the external self: from two to twelve years (preschool and school age). This stage is predisposed to the entry of information, considering the concept of success and failure and the relationship with adults. At school age, self-concept is formed from what others perceive and communicate about the concept that you have of yourself. The cover of the inner self: the individual seeks to describe their identity, making this stage more differentiated and less global. Although part of the self-concept is already built, this stage seeks to define itself in terms of social self-assessment.

The types of self-concept are: physical, personal, social and academic (Cazalla \& Molero, 2013). The physical self-concept refers to the idea that the individual has of himself considering the dimensions of physical ability and physical appearance as fundamental, but also includes physical attractiveness, physical competence, physical form, health and strength.

The personal self-concept refers to the idea that the individual has of himself. It consists of four dimensions: the affective-emotional self-concept is how the individual sees himself with respect to the regulation of his emotions; 
the ethical-moral self-concept is how the individual is considered with respect to honesty; the self-concept of autonomy is how the individual makes decisions about his life according to his own criteria; and the self-concept of self-realization is how the individual looks, with respect to the achievement of their life goals (Cazalla \& Molero, 2013).

The social self-concept represents the perception people have of social skills, the pro-sociality, aggressiveness, and assertiveness, among others, i.e. social interactions established with other people, and is calculated from the behavior observed in different social contexts. This set of skills can be grouped into categories of social competence and social acceptance (Cazalla \& Molero, 2013).

The academic self-concept is subdivided into the perception of competition that exists on various school subjects, such as English, history, mathematics or science. In addition, another subdomain is introduced that is called the artistic self-concept, which could in turn be constituted by partial self-perceptions about dance, dramatic art, plastic arts or musical skills (Cazalla \& Molero, 2013).

\section{SELF-ESTEEM}

General self-esteem or global self-assessment is defined as the degree to which a person likes themselves. It is used as a separate scale, consisting of items that do not contain contents of specific domains and which refers to the personal value of oneself; this implies having a value judgment and an affect that accompanies it (Pastoret al., 2003; Alcaide et al., 2009).

Self-esteem is a consequence; that is, it is the product of practices that are generated inside the individual since childhood, it is more than an opinion or a feeling, it is a motivating force that inspires a type of behavior, and influences actions (Braden, 1995; Pastor et al., 2003; Alcaide et al., 2009).

The importance of self-esteem is that it is fundamental in life, since it is the confidence of the ability to think and face the challenges of life, is the confidence in the right to succeed and be happy, is the feeling of being respected, worthy, having the right to affirm the needs and shortcomings that arise in the course of life, and enables one to reach the established moral principles and enjoy the fruit of efforts. Its essence lies in trusting the mind and knowing that it deserves happiness, which gives an individual a better life.

Self-esteem interferes with every aspect of existence, including job development, dealing with people, what you want to achieve or do achieve, the person with whom the individual falls in love, and the manner in which they relate to their spouse, children and friends (Braden, 1993; Braden, 1995).

High self-esteem is related to rationalism, realism, intuition, creativity, independence, flexibility, the ability to accept changes and correct errors with benevolence and the ability to cooperate in various situations of life. High self-esteem causes the individual to make an effort in the face of difficulties; these people persist in the tasks or objectives proposed, given that if they persevere it increases the probability of obtaining more success than failure. High self-esteem causes self-respect; therefore, the external environment will respond with that same respect. The healthier the selfesteem, the more the individual will be inclined to treat others with respect, benevolence, good will and justice; the development of personal worth leads people to be kind, generous, cooperative and happy (Braden, 1993; Braden, 1995).

Low self-esteem is related to irrationalism, blindness to reality, rigidity, fear of the new and unknown, a low degree of conformity, an inadequate rebellion, being on the defensive, repressed behavior of excessive ways and a fear of others. Low self-esteem causes the individual to fall behind the difficulties of life or to try, but without giving the best of himself, since not persevering increases the probability of obtaining more failure than success. Low self-esteem does not enable one to respect oneself; therefore, the external environment will not respond with respect, but rather with abuse or exploitation towards the individual. This seeks the challenge of the known and the lack of demand, giving the individual more security; however, limiting themselves to the easy and familiar further weakens self-esteem. Negative self-esteem is related to negative affections such as: pain, anguish, doubt, sadness, emptiness, guilt, and shame. 
PSYCHOSOCIAL IMPACT OF DENTOFACIAL ESTHETICS

When studying the previous concepts, it is evident that esthetic appearance influences the improvement of self-concept and self-esteem. Self-esteem could also be affected by the rejection of the body image perceived by itself (Pastor et al., 2003; Braden, 1995).

Physical appearance is a very important factor when establishing social interactions, especially in adolescents and young adults. It has been shown that physical appearance plays a fundamental role in the psychosocial state of a person, especially when evaluating facial esthetics, such as the eyes and mouth, which seem to be important characteristics since they are mobile organs and apparently the first focus of the individual when engaging in a conversation.

The smile is fundamental for the expression of esthetics in the face, and therefore the teeth contribute to this expression. As a result, it is reasonable to expect that dental appearance may also affect the psychosocial state of the individual (Gavric et al., 2015). In addition, the dentofacial appearance influences the kindness, social class and acceptance perceived by the rest. On the other hand, people trust a person who smiles more than a person who does not (Correa, 2015).

To refer to the concept of psychosocial well-being, the term quality of life is often used. This is defined as: the feeling of well-being or lack of well-being that results in satisfaction or dissatisfaction, with the domains of life (Gavric et al., 2015). Quality of life is also considered as the "perception of the individual of his/her position of life in the context of the culture and the value systems in which he/she lives, in relation to their objectives, expectations, standards and concerns". This is close to the well-being of the individual, not only in the absence of the disease, but also to physical, mental and social well-being (Correa, 2015).

Based on this, it is possible to establish that an alteration in oral health contributes to the alteration of quality of life, for which reason the term oral health-related quality of life has arisen (Gavric et al., 2015). The most frequent pathologies of the oral cavity are dental caries and periodontal disease, of average frequency are dental malocclusions and of variable frequency are oral cancer, alterations in dental tissues, maxillofacial traumatisms and dental fluorosis (Puertes, 2013).

In relation to malocclusions, the demand for orthodontic treatment is motivated by the interest in an improvement in the appearance and acceptance. However, methods that estimate the need for treatment are based on occlusal indexes or standard measures. This reflects only the point of view of the professional with regard to the ideal and standard; at this point, there is no assessment of the expectations and real needs of the patient considering whether it is necessary to intervene or not in certain situations, leaving aside the quality of life in oral health (Puertes, 2013).

The oral health-related quality of life, specifically in relation to dentofacial esthetics, can be evaluated through the Psychosocial Impact of Dental Aesthetics questionnaire (PIDAQ) (Gavric et al., 2015). This questionnaire considers the patient in relation to their perception of the malocclusion, and how it affects quality of life and social aspects. This considers more than just the severity of the malocclusion based on established parameters and measurements (Gavric et al., 2015).

The questionnaire of Psychosocial Impact of Dental Aesthetics (PIDAQ) is an instrument that was designed by Klages et al.; there are currently versions in four languages. This instrument was tested in young adults, showing good reliability, revealing a Cronbach's alpha ranging from 0.85 to 0.91 for the four subscales of the questionnaire (Puertes, 2013).

\section{EVIDENCE ON DENTOFACIAL ESTHETICS AND SELF-ESTEEM}

The evidence regarding the impact of malocclusions and their relationship with general selfesteem and psychosocial disorders of dentofacial esthetics is varied; there is no direct association between these three measurements in all cases. Below, we present some studies of interest.

De Paula et al. (2009) conducted a study that included a sample of 301 adolescents, using DAI, PIDAQ and other measures such as the impact of oral health (0HIP-14). The results revealed that the self-perceived 
impact of dental esthetics is influenced by the severity of malocclusion, oral health-related quality of life and body satisfaction. Kolawole et al. (2014) published a study with a sample of 99 dental students, using PIDAQ, DAI and other instruments such as the esthetic component scale (CA) of the Orthodontic Treatment Necessity Index (IOTN), and concluded that the self-perceived psychosocial impact of dental esthetics is related to the severity of the malocclusion. Cartes-Velásquez et al. (2010) conducted a study in a rural high school in the city of Ralco, including a sample of 129 young people, using DAI and a questionnaire containing five questions about psychosocial impact of malocclusion. Severe malocclusion was found in $21.7 \%$ of cases, which is higher than that reported by international studies, showing that malocclusion causes problems in social relationships with peers, and affects women to a greater degree. Jutt et al. (2017) conducted a study with a sample of 108 individuals with an average age of 27 years who needed orthodontic treatment, using PIDAQ and DAI. He established that these individuals are anxious to improve their appearance and obtain social approval.

This association is verified in the same way in the systematic review by Dimberg et al. (2015) about malocclusions of child and adolescent patients and its relationship with psychological and social disorders, as well as oral health-related quality of life. They found four studies with a high level of quality, reporting that the previous malocclusion had a negative impact on oral health-related quality of life predominantly in the dimensions of emotional and social well-being.

Lukez et al. (2015) conducted a study that included a sample of 155 individuals between 12 and 39 years old using PIDAQ, and the Rosenberg self-esteem scale (RSS). They found that women presented a greater psychological influence over dental esthetics, while in the men and elder groups, the malocclusion had a greater psychosocial impact than the mini- and micro-esthetic parameters, estimating that people are not focused on the details of the smile, but on the poor position of the teeth. Gavric et al. (2015) conducted a study with a sample of 200 university students aged from 13 to 33 years, using RSS, PIDAQ and DAI; they showed that with increasing severity of malocclusion, the quality of life in relation to cosmetic dentistry decreases. It was established that self-esteem seems to be more influenced by the selfperceived psychosocial impacts of dental esthetics than by age and gender. Venete et al. (2017) sampled 301 students from the faculty of medicine and dentistry, using PIDAQ and RSS, and found that there is lower self-esteem with a greater psychosocial impact (negative association), but that there is a positive association between PIDAQ and perfectionism. In terms of prevalence, perfectionism and PIDAQ were higher in men.

However, Mafla et al. (2011) performed a study that included a sample of 387 adolescents, using DAI, RSS and socioeconomic level measurement (SES). This group showed a weak correlation between dental esthetics and self-esteem, but found that these can fluctuate when considering another variable such as socioeconomic level; this suggests that there may be other variables that could be associated with dental esthetics and selfesteem, such as peers, family relationships, and close links, among others.

The previously detailed studies reveal the association that exists between malocclusion, general self-esteem and psychosocial disorders in relation to dentofacial esthetics. The majority of studies are in adolescent populations at the national and international level. This shows the lack of studies in a young or university-age population, which is of interest to the fields of dentistry and public health.

\section{REFERENCES}

Alcaide M. Influencia en el rendimiento y autoconcepto en hombres y mujeres. REID. 2009; (2):27-44.

Badran SA. The effect of malocclusion and self-perceived aesthetics on the self-esteem of a sample of Jordanian adolescents. Eur J Orthod. 2010;32(6): 638-644.

Barrachina C. Etiopatogénia: Factores Generales. En: Canut J. Ortodoncia Clínica y terapéutica. 2a ed. España: Elsevier Masson; 2000.

Braden N. El poder de la autoestima: cómo potenciar este importante recurso psicológico. 1a ed. Barcelona: Paidós; 1993.

Braden N. Los seis pilares de la autoestima. 1' ed. Barcelona: Paidós; 1995.

Cartes-Velásquez R, Araya E, Valdés C. Maloclusiones y su impacto psicosocial en estudiantes de un liceo intercultural. Int. J. Odontostomat. 2010; 4(1):65-70.

Cazalla N, Molero D. Revisión teórica sobre el autoconcepto y su importancia en la adolescencia. REID. 2013;43-64.

Correa M. Impacto psicosocial de la estética dental en personas sometidas a blanqueamiento dental [tesis de grado]. Santiago: Facultad de Odontología, Universidad de Chile; 2015. 
de Paula DF, Santos NCM, da Silva E, Nunes MF, Leles CR. Psychosocial Impact of Dental Esthetics on Quality of Life in Adolescents. Angle Orthod. 2009;79(6):1188-93.

Dimberg L, Arnrup K, Bondemark L. The impact of malocclusion on the quality of life amog children and adolescents: a systematic reviw of quantitative studies. Eur J Orthod. 2015;37(3):238-247.

Gavric A, Mirceta D, Jakobovic M, Pavlic A, Zrinski MT, Spalj S. Craniodentofacial characteristics, dental esthetics-related quality of life, and self-esteem. Am J Orthod Dentofacial Orthop. 2015;147(6):711-8.

Jutt I, Bhut A, Rehman A, Memon W. Dental aesthetic; psychosocial impact in patients visiting opd of liaquat university hospital Jamshoro. Professional Medical J. 2017; 24(2):347-351.

Kolawole K, Abjabe $\mathrm{H}$, Otuyemi 0 . Impact of malocclusion on oral health related quality of life of final year dental students. Odontostomatol Trop. 2014; 37(145):64-74.

Lukez A, Pavlic A, Trinajstic M, Spalj S. The unique contribution of elements of smile aesthetics to psychosocial well-being. J Oral Rehabil. 2015;42(4):275-81.

Mafla A, Luna E, Sánchez N, Barrera D, Muñoz G. Estética dental y autoestima es adolescentes. Colombia Médica. 2011;42(4):482-489.

Papalia D, Wendkos S, Duskin R. Psicología del desarrollo de la infancia a la adolescencia. 10 a ed. México: McGraw-Hill; 2009.

PastorY, Balaguer I, García M. El autoconcepto y la autoestima en la adolescencia media: análisis diferencial por curso y género. Rev Psicol Soc. 2003;18(2):141-159.

Puertes N. Necesidad de tratamiento ortodóncico e impacto psicosocial de la estética dental en los adolescentes de la comunidad valenciana [Tesis de grado]. Valencia: Facultad de Medicina y Odontología, Universidad de Valencia; 2013.

Saliba C, Isper A, Moreira R, Saliba N, Gongalvez P. La Salud Bucal en la Percepción del Adolescente. Rev Salud Publ. 2009; 11(2):268-277.

Soto L, Tapia R, Jara G, Rodríguez G, Urbina T. Diagnóstico nacional de salud bucal del adolescente de 12 años y evaluación del grado de cumplimiento de los objetivos sanitarios de salud bucal 2000-2010. Santiago: Ediciones Universidad Mayor; 2007.

Venete A, Trillo-Lumbreras E, Prado-Gascó V-J, Bellot-Arcís C, Almerich-Silla J-M, Montiel-Company J-M. Relationship between the psychosocial impact of dental aesthetics and perfectionism and self-esteem. J Clin Exp Dent. 2017; 9(12): 1453-e1458.

Vicent M, Lagos N, Gonzálvez C, Inglés C, García J, Gomis N. Diferencias de género y edad en autoconcepto en estudiantes adolescentes chilenos. Rev Psicol Univ Chile. 2015; 24(1):1-16. 